\title{
"Conformándonos con los rituales de no cantar cosas profanas [y] sí devotas". Escenografia y música en la celebración del Entierro de Cristo en el Real Colegio-Seminario de Corpus Christi de Valencia (1692)
}

\author{
"Complying with the rituals of not singing \\ secular but devotional things". Scenography and \\ Music during the celebration of the Burial \\ of Christ at the Real Colegio-Seminario \\ de Corpus Christi in Valencia (1692)
}

El Real Colegio-Seminario de Corpus Christi deValència fue fundado por el arzobispo Juan de Ribera (1532-1611) con su propia fortuna, aunando la búsqueda de un nuevo paradigma religioso y cultural - propia del Concilio de Trento- con el deseo de dejar establecido un colegio de clérigos. Ribera se erigió en patrón de los diferentes artistas que materializaron exquisitamente unos espacios concebidos para ejecutar ceremonias minuciosamente diseñadas; estas darían vida a las Sagradas Escrituras, según el propio Ribera entendió, proscribiendo o ignorando algunas celebraciones. Es el caso del Entierro de Cristo, que no comenzó a realizarse hasta 1692 merced al sufragio de una persona desconocida. El presente artículo ofrece los detalles de esta celebración y presenta los motetes inéditos de Máximo Ríos con textos del Evangelio según san Juan y el Libro de Isaías, elección acorde al oficio del Triduo Sacro y razonada en la documentación de la época para evitar el canto de los salmos Miserere e In exitu Israel y del himno Vexilla Regis.

Palabras clave: Colegio-Seminario de Corpus Christi, València, Máximo Ríos, Semana Santa, Entierro de Cristo, motete, paisaje sonoro.

The Real Colegio-Seminario de Corpus Christi in Valencia was founded by the Archbishop Juan de Ribera (1532-1611) with his own fortune, combining the search for a new religious and cultural paradigm -characteristic of the Council of Trent-with a desire to set up a college of clerics. Ribera became the patron of the different artists who exquisitely produced spaces conceived to perform carefully designed ceremonies; these would give life to the Holy Scriptures used at the will of Ribera himself, prohibiting or ignoring certain celebrations. This is the case with the Burial of Christ, which did not begin until 1692 with help from an unknown person. This article provides the details of this celebration and presents the unpublished motets of Máximo Ríos, with texts from the Gospel of John and the Book of Isaiah, a choice in accordance with the office of the Holy Triduum and argued in the documentation of the period to avoid the singing of the psalms Miserere and In exitu Israel and of the hymn Vexilla Regis.

Keywords: Colegio-Seminario de Corpus Christi, Valencia, Máximo Ríos, Holy Week, Burial of Christ, motet, soundscape. 


\section{Introducción}

El Real Colegio-Seminario de Corpus Christi de Valencia, así como su capilla $^{1}$, fue fundado por el sevillano san Juan de Ribera (1532-1611). Ribera fue arzobispo de Valencia y Patriarca de Antioquía a instancia de Felipe II desde 1568 hasta su fallecimiento en $1611^{2}$. Su ascendencia noble ${ }^{3}$ le proporcionó una esmerada educación, una posición social y política aventajada y una importante fortuna con la que pudo fundar esta institución siguiendo el mandato de erigir seminario de clérigos del Concilio de Trento (1545$1563)^{4}$. Las obras se iniciaron en 1586 y finalizaron en 1611, periodo en que "la arquitectura valenciana había adoptado plenamente el lenguaje renacentista, basado en los órdenes y las proporciones establecidos en los tratados de arquitectura de Vitruvio, Alberti y Serlio" ${ }^{5}$. En el edificio encontramos también elementos de la tradición valenciana como las bóvedas de ladrillo realizadas con refinadas técnicas de estereotomía. La iglesia, toda cubierta de pinturas al fresco,

Es uno de los elementos más destacables del Colegio y significa la aparición en València de un nuevo modelo eclesial que rompía con la característica tipología medieval de iglesia parroquial. Siguiendo las directrices contrarreformistas de las Instructiones fabricae de Carlos Borromeo, adopta la planta de cruz latina, cúpula con cimborio con linterna en el cruce, espaciosa nave central de dos tramos con capillas laterales poco profundas, un tercer tramo que corresponde al coro alto a los pies. La capilla mayor con cabecera plana, al estilo escurialense, prescinde de la tradicional forma poligonal. Esta forma se amoldaba a las exigencias del fundador, que no quería una iglesia que sobresaliese al modo parroquial, sino una capilla con acceso exclusivo por el vestíbulo ${ }^{6}$.

\footnotetext{
${ }^{1}$ En adelante será mencionado como el Colegio.

${ }^{2}$ Me referiré a él como Juan de Ribera, Ribera o el Patriarca indistintamente. Fue beatificado en 1796 y canonizado por Juan XXIII en 1960.

${ }^{3}$ Era hijo de Per Afán Enríquez de Ribera y Portocarrero (Sevilla 1509; Nápoles 1571). Como virrey de Nápoles, Per Afán convivió con numerosos e importantes artistas cercanos a la corte virreinal, desarrollando el gusto por las antigüedades clásicas, de las que adquirió una importante colección, lo que explicaría "que don Juan de Ribera heredara esta pasión, pues entre su colección se encontraban piezas clásicas de gran valor, algunas, como los bustos de emperadores romanos, pudieron ser herencia de los que poseyó su padre". Raúl Romero Medina: "Tened poco aderezo y muy honesto'. El mecenazgo de don Juan de Ribera en el arzobispado de Sevilla: la fundación del colegio-hospital de la sangre y del convento del Corpus Christi en Bornos (1571-1597)", El Patriarca Ribera y su tiempo. Religión, cultura y política en la Edad Moderna, Emilio Callado Estela (ed.), Valencia, Institución Alfonso el Magnánimo, 2012, p. 571.

${ }^{4}$ Constituciones de la Capilla del Colegio y Seminario de Corpus Christi [1610], Valencia, Imprenta de Antonio Bordázar, 1739, cap. I, introducción (https://bivaldi.gva.es/va/catalogo_imagenes/grupo.do?path=1005348, consulta 21-10-2020). En adelante serán mencionadas simplemente Constituciones.

${ }^{5}$ Carmen Rodrigo Zarzosa: "Un programa iconográfico en torno a la eucaristía", Religiosidad y ceremonias en torno a la eucaristía, Actas del Simposium octubre 2003, Francisco Javier Campos y Fernández de Sevilla (coord.), San Lorenzo de El Escorial, Instituto Escurialense de Investigaciones Históricas y Artísticas, 2003, vol. 2, p. 738.

${ }^{6}$ C. Rodrigo Zarzosa: “Un programa iconográfico ", p. 739.
} 
Los frescos son obra del italiano afincado en Cuenca Bartolomé Matarana (Génova ca. 1550-1625) con un programa iconográfico claramente contrarreformista que desarrolla la advocación del Corpus Christi y la adoración a la Eucaristía por los Santos.

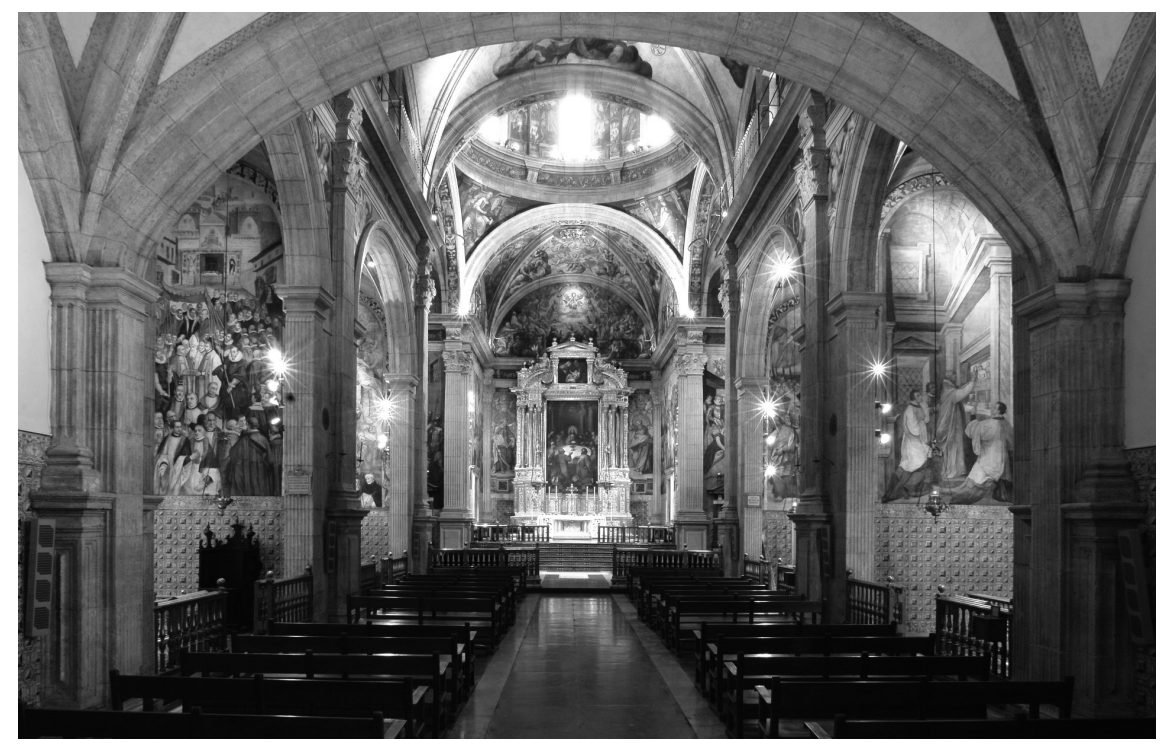

Ilustración 1. Colegio-Seminario de Corpus Christi, iglesia ${ }^{7}$

Dominando la profusa decoración pictórica de la iglesia ${ }^{8}$, preside el altar una Cena encargada por el Patriarca en 1606 al solsonés Juan Ribalta (1565-1628). Tras ella, desde 1606 y mediante un complejo sistema de poleas, se descubre todos los viernes del año un Cristo crucificado del siglo XVI procedente de Silesia ${ }^{9}$. Cuatro capillas laterales completan la iglesia, destacando la de laVirgen

\footnotetext{
${ }^{7}$ Si no se indica lo contrario, todas las imágenes de este artículo se corresponden con fotografías cedidas y reproducciones autorizadas por el Colegio Seminario de Corpus Christi, Valencia.

${ }^{8}$ Para una explicación del Colegio desde el punto de vista arquitectónico y para un recorrido gráfico y descripción de sus espacios, así como un plano del mismo, véase Joaquín Bérchez, "El Colegio del Patriarca en la cultura artística de su tiempo" (http://joaquinberchez.com/projects/el-colegio-del-patriarca-en-la-cultura-artistica-de-su-tiempo/, consulta 21-10-2020).

9 "El cuadro actúa de tapa corrediza ocultando la imagen de un impresionante crucifijo [...], obra germánica cincocentista cuya cabeza, de patética expresividad, fue hallada enterrada en Silesia a mediados de siglo XVI. Completada la imagen en 1576 la adquirió Rodolfo II de Praga quien la donó a doña Margarita de Cardona [...] cediéndola al Patriarca Ribera en 1601. Los prodigios que se le atribuían la consolidaron como la principal reliquia del Colegio disponiendo el Patriarca que se le diera culto especial en el altar mayor". Fernando Benito Doménech: Real colegio y museo del Patriarca, València, Consell Valencià de Cultura, Generalitat Valenciana, 1991, p. 43.
} 
de la Antigua, "cuya Imagen hicimos sacar à un gran Pintor, de la misma manera que está la figura de nuestra Señora de la Antigua en la Iglesia Catedral de Sevilla $[\ldots]^{\prime \prime 10}$.
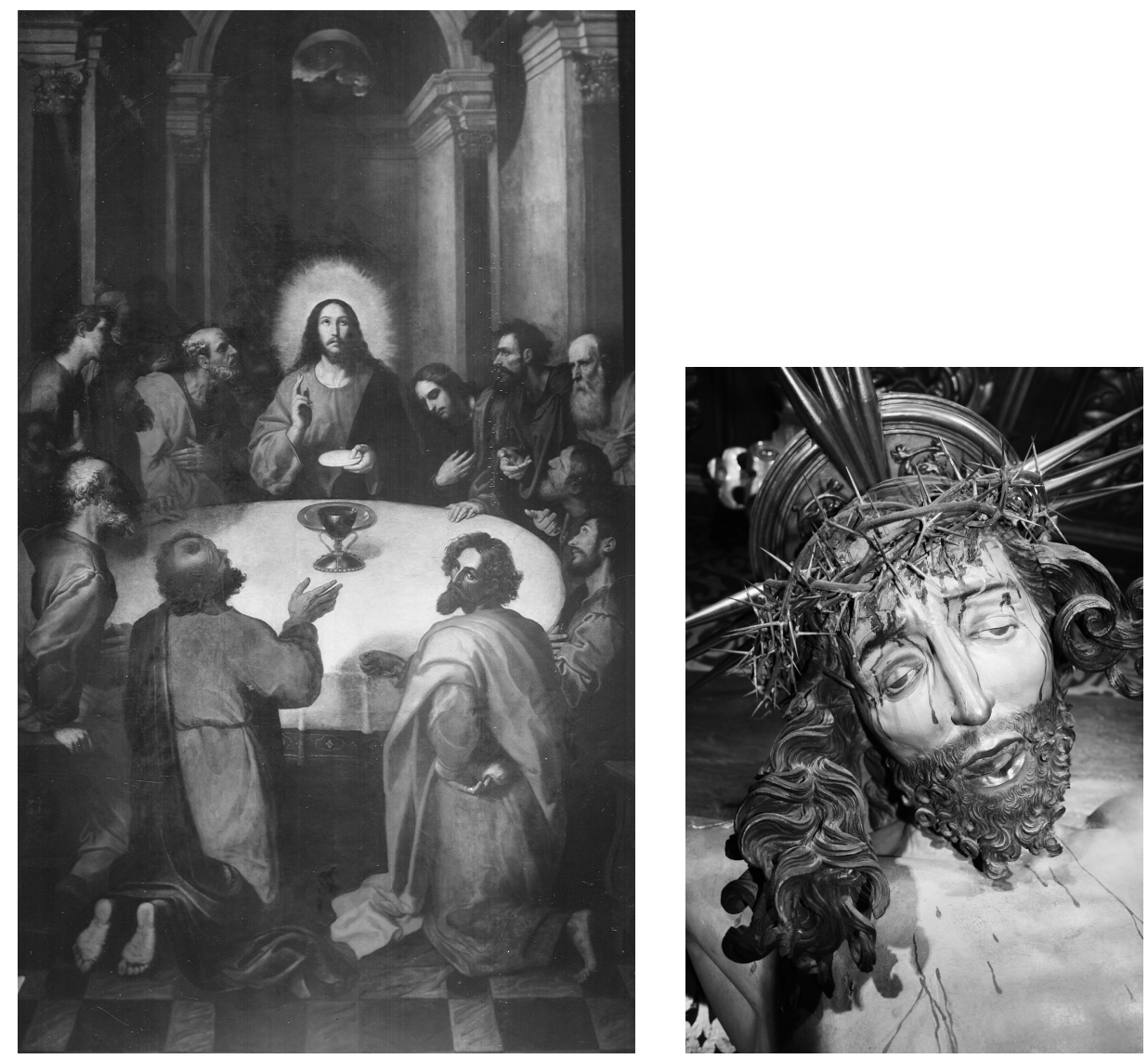

Ilustraciones 2 y 3. Cena de Francisco Ribalta (1565-1628), y Cristo crucificado (detalle), casilicio trasero, retablo de la iglesia

A la derecha del acceso al claustro se encuentra la capilla del Monumento, conocida también como capilla de la Inmaculada Concepción debido a que el altar está presidido por una Inmaculada de Gregorio Fernández desde 1639. Fue edificada para instalar el monumento de Jueves Santo y en ella se celebraría el Entierro de Cristo objeto de este artículo. Su bóveda,

\footnotetext{
${ }^{10}$ Constituciones..., cap. XXXI-3.
} 
[...] está pintada por Tomás Hernández (1606) con escenas alusivas al Sacrificio de la Cruz tomadas del Antiguo Testamento [...] y en el presbiterio ángeles portando los símbolos de la Pasión [...]. A los lados del altar hay encastrados dos lienzos, uno de mano valenciana con Cristo a la columna [...], otro con la Oración del Huerto, copia de un original de Antonio Campi [...]. En el banco del altar se aloja una interesante talla de Cristo yacente realizada por Gaspar Giner en 1608, encargada por el Patriarca precisamente para los oficios de Jueves Santo ${ }^{11}$.
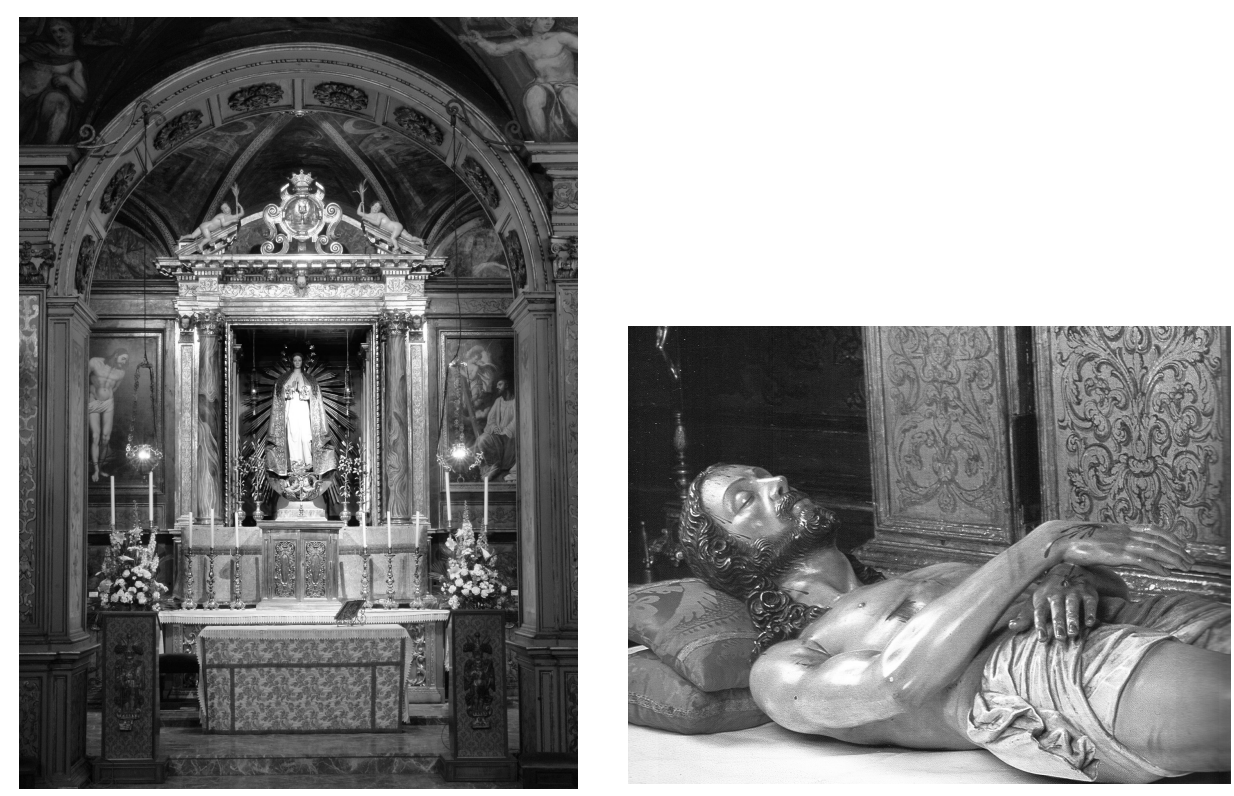

Ilustraciones 4 y 5. Capilla del Monumento o de la Inmaculada Concepción y Cristo yacente de Gaspar Giner (1608)

Completa el edificio un claustro de dos pisos recubierto con cerámica de Manises y rematado por cincuenta y seis columnas de mármol de Carrara "de orden toscano traídas de Génova. Se instalaron para que formaran dos galerías de arcos de medio punto, cubiertas de bóveda de arista, que logran configurar un espacio único en la ciudad [...]"12. El conjunto arquitectónico y artístico descrito será el escenario en el que cobrarán vida sonora las diversas ceremonias previstas en las Constituciones: la música y la palabra, vestirán con su reverberación los diferentes espacios de manera efímera, pero sin duda espectacular.

\footnotetext{
${ }^{11}$ Fernando Benito Doménech: Real colegio y museo del Patriarca..., 1991, p. 45.

${ }^{12}$ Daniel Benito Goerlich: "Juan de Ribera y las artes: sensibilidad, gusto y aliño al servicio de una fe sincera", El legado del Patriarca Juan de Ribera, IV centenario, Valencia, Consorci de Museus-GVA / Real Colegio Seminario de Corpus Christi, 2011, p. 27.
} 


\section{El oficio divino y la celebración de la Semana Santa}

El Patriarca procuró compatibilizar la celebración de la liturgia con las actividades propias de un seminario eclesiástico. Para cumplir este propósito, plasmó en las constituciones de la capilla una estricta etiqueta en la que la solemnidad era reforzada por la pausa y sosiego de la interpretación del canto ${ }^{13}$, limitando además los oficios a las horas de tercia, sexta, misa conventual polifónica, nona, vísperas y completas ${ }^{14}$, y maitines solamente en Navidad y Semana Santa ${ }^{15}$, para que "con mayor suavidad, y comodidad pudiessen cantar los oficios divinos con pausa, y sosiego, que es el fin principal que hemos tenido [...] de que aya una Iglesia en esta Ciudad, en la que se le den alabanzas con el respeto, atención, y veneración que se debe à tan infinita Magestad, para exemplo de los demás, así del Reyno, como de fuera de él"16. Además de limitar las horas del oficio, designó tres misas semanales - de jueves, viernes y sábado-, como de especial advocación:

Aunque según lo ordenado por el Oficio Romano, las Missas Conventuales han de ser de Feria, ò del Santo que cae en tal día, no se impide, ni prohíbe que se pueda mudar esta regla por algunas causas graves, principalmente en esta nuestra

${ }^{13}$ En atención a la mayor o menor solemnidad de la festividad (o feria), el Patriarca mandaba "que en todas las horas se haga mediación conocida en la metad de los versos [...] y que los días de fiestas solemnes sea mayor [...]". Constituciones..., cap. XXXIX-4. En relación al canto de los salmos, añadía que "la cantoría no vaya picada, sino con pausa, y sosiego, y que se haga mediación conocida en medio del verso, mayor, o menor, según la solemnidad de la fiesta". Constituciones..., 1739, cap. XL-3.

${ }^{14}$ Constituciones..., cap. XXIV.

${ }^{15}$ Los maitines de Navidad eran celebrados a puerta cerrada en canto llano (en las Constituciones se indica en tono), entre las diez y las doce de la noche. Los de Semana Santa comenzaban a las 14:30 h para finalizar antes de que cayera la noche, por lo que vísperas y completas quedaban suprimidas. Eran en canto llano salvo el Benedictus y el Miserere, alternatim canto llano-fabordón y algunos sencillos en canto de órgano (Constituciones..., 1739, caps. XL-21 y LIV-5). Las Constituciones mencionan las diferentes formas de interpretar el oficio cantado en el Colegio de la siguiente manera: en tono (canto llano), en canto de órgano y en música (polifonía vocal escrita), contrapunto (polifonía vocal improvisada), en fabordón escrito o improvisado. Estas indicaciones guardan similitudes con las del Calendario y Constituciones de la Capilla de Borgoña [E-Mpa, Administrativa, leg. 1133], copiados expresamente para Felipe II, "y que constituyen un ceremonial basado en los diferentes tipos de intervención musical, cantada fundamentalmente [...]. Cuatro son los tipos de canto que aparecen: in tono, in contrapunto, in fabordón e in musica. Sin duda, el primero se refiere al canto llano [...]. In musica hace referencia a lo que entendemos modernamente por polifonía, lo que en la época se denomina canto de órgano o canto figurado, es decir, la manera más elaborada de disponer un discurso vocal polifónico. Entre ambos extremos, se sitúan el contrapunto, improvisación (o práctica semi-improvisada) de una o más voces sobre una melodía dada, y el fabordón, especie de recitado acórdico [...]". Luis Robledo Estaire: "La música en la casa del rey", Aspectos de la cultura musical en la Corte de Felipe II, Madrid, Fundación Caja Madrid, 2000, pp. 111-112, 163-164. Las Constituciones borgoñonas están reproducidas en el mismo volumen, pp. 327-332.

${ }^{16}$ Constituciones..., cap I-p. 6. 
Iglesia [...] que hemos construido, y dotado por nuestra devoción [...] para que en tres días de la semana [...] Jueves,Viernes, y Sábado, se diga la Missa Conventual de las festividades siguientes $[\ldots]^{17}$.

Continúa el citado mandato indicando los tres días: Jueves, del Santísimo Sacramento, a excepción de Jueves Santo y festividades de primera y segunda clase, se celebraba misa solemne con canto de órgano. Tras esta, tenía lugar la Procesión de las Espigas en el interior del templo, en la que se interpretaba en canto llano una selección de textos del Antiguo Testamento realizada por el propio Patriarca ${ }^{18}$ y se ofrendaban doce urnas con espigas de trigo, "acordándonos de que Dios nuestro Señor [...] ordenó al santo Moysés, que después de averle fabricado Altar, mandasse, que doce personas, una de cada Tribu, offreciessen en él, como lo hicieron"19. Por la tarde, tenían lugar las completas solemnes con ministriles ${ }^{20}$. Viernes, de las llagas de Jesucristo, a excepción de Viernes Santo y festividades de primera y segunda clase, tras la misa solemne en canto de órgano, se cantaba el Miserere en tinieblas frente a la Cruz de Silesia que era descubierta a medida que este se interpretaba ${ }^{21}$. Sábado, de la PurísimaVirgen María, misa solemne con canto de órgano y la Salve ${ }^{22}$ "con la misma solemnidad, y música que se ha de decir en las fiestas solemnes de nuestra Señora" ${ }^{23}$. La complejidad del culto establecido refleja el criterio de Juan de Ribera, profundo conocedor de la Biblia, de la que poseía cuarenta y cinco ediciones en su biblioteca: "los estudios bíblicos ocupan un lugar privilegiado en ella. Es una característica que se quiso destacar al organizarla [...] a fin de sugerir que el resto de los libros allí reunidos constituye, en cierto modo, un complemento al estudio de la Sagrada Escritura" ${ }^{24}$. Ribera ofrecía en sus sermones el sentido alegórico del relato bíblico: "El caudaloso discurso doctrinario contrarreformista está fundamentado en la fuente bíblica y en la Patrística. El destinatario es un público al que adaptar la

\footnotetext{
${ }^{17}$ Ibid., cap. XXXI. Las instrucciones para la especial advocación de los jueves, viernes y sábado, se encuentran en las Constituciones..., caps. XXXII, XXXIII, XXXIV.

${ }^{18} \mathrm{Ibid}$., cap. XXXII. Solamente se interpretaban en fabordón los primeros versos del salmo 116, durante la exposición del Santísimo Sacramento.

${ }^{19}$ Ibid., cap. XXXII-9, en Vicente Castell: "Los Jueves del Patriarca", Analecta sacra tarraconensia, 28, 1955, p. 234.

${ }^{20}$ Ibid., cap. XL-9.

${ }^{21}$ Ibid., cap. XXXV.

${ }^{22}$ Ibid., cap. XL-30.

${ }^{23} \mathrm{Ibid}$., cap. XXXVII-1. Indica que este Oficio se celebrará "todos los sábados no impedidos [...]". Ello excluye el Sábado Santo y sábados que coincidan con festividad de primera o segunda clase.

${ }^{24}$ Miguel Navarro Sorní: "La cultura del Patriarca Juan de Ribera a través de su biblioteca", Studia Philologica Valentina, 15, 2013, p. 226.
} 
nueva pedagogía tridentina, desglosada en un 'luminoso programa' de reforma llevado a cabo entre sínodos y constituciones en las diócesis que regentó como obispo $[\ldots]^{\prime 25}$.

En este contexto, no es casual que una representación paralitúrgica como es el Santo Entierro fuera omitida por Juan de Ribera: en puridad quizá no debiera haberse realizado nunca, pues el santo prohibió "se haga procesión por fuera de nuestra Casa, ni por dentro della, más que la del Santíssimo Sacramento [...] y la del Jueves, y Viernes Santo [...]"26, así como "que en el día de la Assumpción de la benditíssima Virgen María no se ponga cama, sino que se haga el Oficio como los demás solemnes de primera clase" ${ }^{27}$ : estas interdicciones, junto a la nunca cumplida de celebrar danzas ${ }^{28}$, marcan un límite simbólico entre la celebración de un oficio religioso extremadamente sofisticado y de fuerte dramatismo, y la escenificación teatralizada del mismo ritual.

Todo lo referente a la música del oficio divino quedó pautado en el capítulo XL de las Constituciones ${ }^{29}$ : el Domingo de Ramos se cantaba la Pasión según san Mateo de Jan Nasco con canto de órgano ${ }^{30}$, mientras que martes y miércoles, las Pasiones eran en canto llano y algunas secciones a tres voces con canto de órgano. El Jueves Santo, antes de celebrar maitines, tenía lugar la ceremonia de lavatorio de los pies y se trasladaba el Santísimo Sacramento a la capilla del Monumento para la vigilia de oración y canto durante la noche y el día hasta su retorno a la iglesia elViernes Santo, día en que se cantaba la Pasión según san Juan de Juan Bautista Comes en canto llano, algunas secciones a tres voces con canto de órgano y el proceso a cuatro. Cerraba la jornada el oficio de maitines, celebrado en tinieblas y canto llano. Tras este, se cantaba el Miserere alternando

${ }^{25}$ María Laura Giordano: "Dos caras de la contrarreforma: Juan de Ribera y sor Hipólita de Jesús", El Patriarca Ribera y su tiempo. Religión, cultura y política en la Edad Moderna, Emilio Callado Estela (ed.), Valencia, Fundació Alfons el Magnànim, 2012, p. 204.

${ }^{26}$ Constituciones..., cap. LIV-2. La procesión de Jueves y Viernes Santo hace referencia al traslado del Santísimo Sacramento a la capilla del Monumento mencionada antes. Sí se permitían las procesiones exclusivamente en el interior de la iglesia, entre las que estaba la de Domingo de Ramos.

${ }^{27}$ Ibid., cap. LIV-6.

${ }^{28}$ Para una descripción y análisis de las danzas del Corpus del Colegio, véase Mireya Royo: "Les danses de Juan Bautista Comes per al cap de l'octava de Corpus Christi al Col.legi del Patriarca: espectacle devocional i exaltació de la monarquia", Paraules al concert: transferencia de conocimiento en la conferencia-concierto, un modo de escucha para la educación del siglo XXI, Ana M. ${ }^{a}$ Botella Nicolás (ed.), Valencia, Universitat de Valencia, 2020, pp. 86-101.

${ }^{29}$ La celebración y ritos de la Cuaresma y la Semana Santa en el Colegio se encuentra desarrollada en Mireya Royo: "La celebración de la Cuaresma y la Semana Santa en el Colegio Seminario de Corpus Christi de Valencia en el siglo XVII: entre la tradición y la renovación musical", La música a la Corona d’Aragó: investigació, transferència i educació, Rosa Isusi, Francesc Villanueva (eds.), Valencia, Universitat de València, Institut de creativitat i innovacions educatives, en prensa, pp. 151-165.

${ }^{30}$ Sobre esta Pasión, véase Greta Olson: "Mixing chant traditions: An Italian Passion in Spain", Alamire Yearbook, IV, 2001, pp. 413-432. 
un verso en fabordón y otro en canto llano, excepto los versos Tibi soli peccavi, y Benigne fac Domine con canto de órgano, y el Benedictus, alternatim canto llano $\mathrm{y}$ fabordón ${ }^{31} \mathrm{y}$ algunos sencillos ${ }^{32}$ con canto de órgano.

\section{La celebración del Entierro de Cristo y los motetes atribuidos a Máximo Ríos, maestro de capilla (1686-1705)}

El oficio de Viernes Santo se celebró, como se ha explicado arriba, hasta 1692, año en el que, por primera vez, se incorporó al mismo la celebración del Entierro de Cristo. Isidro Planes, ayudante de sacristán, redactó en la Consueta todas las vicisitudes de la celebración: "Determinado que estuvo el hazerse el entierro de Christo no causó poca dificultad elegir puesto, y hazerse en él el sepulcro digno depósito de tal señor" 33 . Una carta de pago por la fabricación del sepulcro informa del sufragio que propició su creación ${ }^{34}$ y aclara que este fue colocado donde previamente se había erigido el monumento al Santísimo Sacramento el Jueves Santo y donde durante el año se encontraba el Cristo yacente de Gaspar Giner que desde la Semana Santa de 1608 salía en procesión por la iglesia:

[...] por haver dorado y estofado de negro, y dar de negro bruñido, y dorar las molduras ondeadas, el sepulcro y puertas del, que se ha hecho nuevamente entre las bassis delas columnas del Retablo dela Puríssima Concepción; el qual sepulcro sea echo para colocar decentemente la imagen del Santo Christo, que se expone jueves y viernes Santo para adorar enel Monumento, la qual no había estado jamás en lugar digno ni decente siendo tan linda y venerable imagen como lo es; además que habiendo un

${ }^{31}$ El fabordón era un procedimiento a menudo improvisado -no obstante que Unmack y Hartwell mencionan 59 colecciones escritas solo en Italia-, para el canto de salmos y cánticos (en el Colegio también se cantaba la Salve en fabordón). Era de carácter homofónico, casi siempre a cuatro voces, y se interpretaba respetando la mediación del tono salmódico correspondiente; su uso solía alternar secciones en canto llano o en canto de órgano. Véase John Bettley: "North Italian 'Falsobordone' and its Relevance to the Early 'Stile recitativo', Proceedings of the Royal Musical Association, vol. 103, 1976-1977, pp. 1-18; Susan Unmack and Robert Hartwell: "Baroque Ideals of Text Declamation and Their Relevance to the Falsobordone Genre", BACH: Journal of the Riemenschneider Bach Institute, 14, 4, 1983, pp. 15-24; Philippe Canguilhem: L’improvisation polyphonique à la Renaissance, París, Classiques Garnier, 2015; Giuseppe Fiorentino: "Contrapunto and fabordón. Practices of extempore polyphony in Renaissance Spain", Studies in Historical Improvisation. From Cantare super librum to Partimenti, Massimiliano Guido (ed.), Ashgate, 2017, pp. 72-89.

${ }^{32}$ Las Constituciones reflejan que los sencillos consistían en la interpretación de música polifónica con un solo cantor por voz.

${ }^{33}$ E-VAcp, Consueta Original de la Sacristía, sign. 270 ACC-AR/3-183K, f. 167r. En adelante será mencionada como Consueta. La narración del Entierro, contenida en la Consueta e inédita, se encuentra íntegra en el Anexo.

${ }^{34}$ El novedoso tema de la producción musical que rodea a la muerte y las últimas voluntades, ha sido estudiado por Tess Knighton: "Music for the Soul: Death and Piety in Sixteenth-Century Barcelona", Listening to Early Modern Catholicism: Perspectives from Musicology, Daniele V. Filippi, Michael Noone (eds.), Leiden, Brill, 2017, pp. 233-258. 
devoto que quiere amortizar el entierro de Cristo, no habiendo sepulchro decente ni pudiéndose hazer en otra parte, determinó el Ilustre Colegio se hiziesse para tales funciones, y por ser así hize hazer el presente y lo firmé de mi mano en Valencia a 31 de Agosto 1691. [Firma] Pedro Campos ${ }^{35}$.

Los motetes para el Entierro de Cristo fueron expresamente compuestos para esta nueva ceremonia y atribuidos en las copias existentes al maestro de capilla Máximo Ríos, músico que procedía deVic y fue maestro de capilla desde junio de 1686 hasta su fallecimiento en $1705^{36}$. Los manuscritos se encuentran en el archivo del Real Colegio Seminario de Corpus Christi ${ }^{37}$ : el primer motete es a 8 voces para ser cantado en el presbiterio frente al Cristo yacente; el segundo, a 4 voces para acompañar al Cristo en procesión a su sepultura; el tercero, a 8 voces, es cantado al llegar al sepulcro y contiene una sección separada también a 8 que se canta al correr la lápida ${ }^{38}$.

\section{El motete como género y su presencia en la liturgia del Colegio}

Explica Anthony Cummings que son múltiples y diversas las fuentes manuscritas e impresas que emplean el término "motete" a lo largo del siglo XVI, en ocasiones sustituido por el apelativo canciones sacras para evitar el sentido despectivo de su acepción medieval; casi sin excepción su texto es latino y de carácter religioso, de origen litúrgico a veces, pero también procedente de otras fuentes e incluso nuevamente compuesto y aceptado para uso litúrgico por la Iglesia. En cuanto a la música, "los procedimientos composicionales más refinados de la época están asociados con el género, en contraste con otros géneros vocales sagrados, que emplean ordinariamente una gama más reducida de pro-

${ }^{35}$ E-VAcp, Sacristía, Recibos, órdenes de pago, memoriales, edictos, y gasto menudo, sin catalogar, Carta de pago, 31-8-1691, 20 libras. Las cursivas son de la autora.

36 Joaquín Piedra: "Maestros de Capilla del Real Colegio de Corpus Christi (1662-1822)", Anuario Musical, 23, 1968, pp. 89-98.

${ }^{37}$ El Colegio Seminario de Corpus Christi alberga, junto a la Catedral de Valencia, la mayor colección musical de la Comunidad Valenciana. Sus fondos han sido catalogados recientemente bajo la coordinación de Greta Olson y Rosa Isusi (https://bivaldi.gva.es/va/consulta/resultados_busqueda_restringida.do?presentacion=mosaico\&idOrigen $=1598$ \& tipoResultados\&busq_coleccionsumario=Colecciones+-+Biblioteca+de+Religiosidad+-+Religiosidad+valenciana\&descrip_coleccionsumario=Colecciones+-+Biblioteca+de+Religiosidad+-+Religiosidad+valenciana consulta 21-10-2020). Rosa Isusi Fagoaga, Greta Olson: "Hacia un catálogo colectivo del patrimonio valenciano: el Real Colegio-Seminario de Corpus Christi como primer paso", Boletín DM, 12, 2008, pp. 92-97.

${ }^{38}$ Máximo Ríos (i?-1705): Motetes para el Entierro de Cristo: Abscisus est, a 4; Post haec autem, a 8; Acceperunt, a 8, E-Vacp, sig. Mus/CM-R-32. Actualmente forman un volumen de 29,22 x $31 \mathrm{~cm}$, con manuscritos copiados entre 1710 y 1810 por tres manos diferentes, no conservándose copia del Tiple segundo de primer coro de Post haec autem. En el volumen hay dos acompañamientos idénticos para cada uno de los motetes a 8, y uno para el motete a 4 de copia posterior a los anteriores. 
cedimientos más simples $[\ldots]^{\prime 39}$. La interpretación de motetes toma carta de naturaleza en diferentes celebraciones como género que puede ser libremente utilizado en variadas situaciones. Los diarios de la Capilla Sixtina dejan constancia de su uso no litúrgico, a partir de 1555 durante el ofertorio de la misa y en 1559 tras el Ite, missa est ${ }^{40}$. Otros documentos atestiguan del uso de motetes en procesiones y en la ceremonia del canto de la Salve ${ }^{41}$.

Al finalizar el Concilio de Trento (1563), aparecen numerosas ediciones musicales con colecciones de motetes ordenados a la manera del calendario litúrgico romano ${ }^{42}$ y con textos adecuados a las modificaciones y supresiones realizadas en los nuevos Breviario y Misal (1568 y 1570) ${ }^{43}$. Ello se refleja en casos como el de la catedral de Sevilla, descrito por Juan Ruiz Jiménez, en el que el tracto pretridentino Sicut cervus publicado por Francisco Guerrero para la misa de Requiem en su Liber primus missarum de 1566 era eliminado de la misma en su versión del Missarum liber secundus de 1582. Sin embargo, el mencionado tracto aparece en nuevas copias de esta obra, en la propia catedral de Sevilla y otras catedrales españolas e hispanoamericanas, como motete para la elevación del cáliz. Algo similar sucedía con los responsorios del oficio de difuntos, que recibían la categoría de motetes y eran utilizados también en la elevación ${ }^{44}$.

39 "[...] the most refined compositional procedures of the time are associated with the genre, as contrasted with other sacred vocal genres, which ordinarily employ a narrower range of simpler procedures [...]". Anthony Cummings: "The Motet", European Music: 1520-1640, James Haar (ed.), Woodbridge, The Boydell Press, 2006, p. 132. Salvo indicación contraria, todas las traducciones son de la autora. El estudioso argumenta sobre el repertorio motetístico estrictamente litúrgico y el paralitúrgico; en el primer grupo parecen utilizarse a menudo procedimientos como el fabordón y el alternatim para el canto en su diversidad de posibilidades. Además, en p. 134, aporta evidencia documental del mantenimiento de estas prácticas durante el siglo XVII.

${ }^{40}$ Anthony M. Cummings: "Toward an Interpretation of the Sixteenth-Century Motet", American Musicological Society, 34, 1, 1981, pp. 45-47.

${ }^{41}$ Todd Michael Borgerding: The Motet and Spanish religiosity, ca. 1550-1610, tesis doctoral, University of Michigan, 1997, pp. 61-106. En el Apéndice documental n. ${ }^{\circ} 1$ el autor presenta una lista de textos de motetes y sus fuentes entre 1555 y 1610 ; en el n. ${ }^{\circ}$ 2, un inventario de las colecciones de dichos motetes, y en el Apéndice n..$^{\circ}$, los inventarios de música de la catedral de Sevilla de 1588, 1603 y 1618.

42 "Libros de motetes como estos, al asignar piezas individuales a festividades específicas o tiempos del año litúrgico, imbuyeron el género con un nuevo sentido de orden reformado y disciplina característica del periodo post-tridentino" ["Motet books such as these, in assigning individual pieces to specific feasts or seasons of the church year, imbued the genre with a new sense of reformed order and discipline characteristic of the post-Tridentine period"]. David Crook: "Proper to the Day: Calendrical Ordering in post-Tridentine Motet Books", Mapping the Motet in the Post-Tridentine Era, Esperanza Rodríguez, Daniele Filippi (eds.), Londres, Routledge, 2019, p. 19. Sirva como ejemplo citado por el autor en p. 23, el Motecta festorum totius anni de Palestrina, del que hubo trece ediciones entre 1563 y 1622.

${ }^{43}$ Breviarium Romanum ex decreto ss. Comcilii Tridentini restitutum, Pii V Pont. Max. iussu editum, Roma, Paolo Manuzio, 1568, y Missale Romanum ex decreto ss. Concilii Tridentini restitutum, Pii V Pont. Max. iussum editum, Roma, Bartolomeo Faletti, Giovanni Varisco, 1570.

${ }^{44}$ Juan Ruiz Jiménez: "Mapping the Motet in post-Tridentine Seville and Granada. Repertoire, Meanings and Functions", Mapping the Motet in the Post-Tridentine Era, Esperanza Rodríguez, Daniele Filippi (eds.), Londres, Routledge, 2019, p. 255. Las fuentes en las que Sicut Cervus aparece como motete para la elevación son E-BUa 1, GCA-Gc 3, GCA-Gc 6, MEX-Mc 2. 
El diario de la Capilla Sixtina de 1616 permite concluir que "los motetes que sistemáticamente acompañaban el rezo del ofertorio toman sus textos del oficio más a menudo que de la misa del día [...]" ${ }^{45}$, lo que refleja la orientación didáctica de la liturgia: esta otorgará gran importancia a los tiempos de Septuagésima ${ }^{46}$ y Cuaresma, donde el canto de motetes del evangelio del día contribuye a amplificar la intencionalidad exegética del sermón y la homilía. Ello condicionará a los compositores, que "se enfrentaban a la tarea de ajustar el evangelio a una extensión adecuada preservando al tiempo los hechos decisivos. Para ello, recurrieron a reducciones del evangelio que conocían bien, los cantos del oficio, que eran utilizados como componentes de los textos de los motetes" 47 .

Volviendo al Colegio, las constituciones de la capilla (1610) mencionan el canto de motetes tras la elevación del cáliz en la misa de festividades solemnes, en todas las festividades de la Virgen y durante la ceremonia de la Salve de los sábados (no impedidos por festividad de primera o segunda clase) ${ }^{48}$. Por otra parte, ordenan celebrar las completas de primera clase con canto llano salvo el salmo Nunc dimittis, en el que posiblemente se interpretara un motete: "dirà un verso el órgano, y otro el Coro à fabordón, ò con otra composición, como ahora se hace" ${ }^{49}$. Finalmente, de 1626 se conserva un recibo de pago a varios capellanes por el canto de motetes durante la vigilia de Viernes Santo frente al monumento ${ }^{50}$.

La ceremonia de la Salve en el Colegio guarda numerosas concomitancias con la de la catedral de Sevilla -recordemos que el Patriarca instituyó, en el Colegio, capilla y culto a la sevillanaVirgen de la Antigua-, como se deduce del estudio de Juan María Suárez Martos, en el que presenta, entre otras obras, 8 motetes del Ms. 5-5-20 de la Biblioteca Colombina y 14 del Ms. n. ${ }^{\circ} 1$

45 " [...] the motets that consistently accompanied the recitation of the Offertory more often draw their texts from the Office than from the Mass of the day [...]". A. M. Cummings: "Toward an Interpretation...", p. 48.

${ }^{46}$ El tiempo de Septuagésima abarca las tres semanas anteriores al inicio de la Cuaresma. El domingo de Septuagésima es inmediatamente anterior al Miércoles de Ceniza, a nueve semanas de la Pascua de Resurrección.

47 "Motet composers were faced with the task of trimming the gospel to a manageable length while preserving its key events. For this they turned to condensations of the gospel well-known to them, the Office chants, which were used as building blocks for motet texts". T. M. Borgerding: The motet..., p. 115.

${ }^{48}$ Constituciones..., caps. XXXII-6 y XL-30.

${ }^{49}$ Ibid., cap. XL-8.

${ }^{50}$ E-VAcp. Sacristía, Recibos, órdenes de pago, memoriales, edictos, y gasto menudo. Sin catalogar. Recibo 27-3-1626. 
de la Capilla de la Antigua en la Catedral de Sevilla ${ }^{51}$, aseverando que "los motetes de adoración a la Virgen se solían tomar del libro bíblico del Cantar de los Cantares" 52 .

En cuanto a la elección de los textos de los motetes, esta no quedaba a cargo del compositor, sino que eran previamente seleccionados por un superior de la propia capilla ${ }^{53}$. Es el caso de los motetes para el Entierro de Cristo, como demuestra el memorial ofrecido por Planes en el que detalla las razones por las que se evitaba cantar los salmos 50 y 113, Miserere e In exitu Israel, o el himno Vexilla Regis, cuya función era la de librar al difunto del purgatorio, algo "impropio todo de pedirse por el Alma de Christo [...]"54:

[...] y huimos de cantar el Miserere, y el In Exitu Israel de Egypto, por parecernos no convienen para esta función, pues en cantar el Miserere la Iglesia por medio de los ecclesiásticos es pedirle a Dios tenga misericordia del Alma del Difunto o difunta y la saque del Purgatorio.Y en el In Exitu sele pide lo mesmo a Dios, pues en el Egypto tierra de captividad está representado el Purgatorio, captiverio de las Almas, y por la tierra de promisión y desseada adonde desseavan llegar los Isrraelitas, está significado el cielo adonde dessean llegar las Almas, con que le piden lo mesmo a Dios que en el Miserere, impropio todo de pedirse por el Alma de Christo no bien que otros cantan Vexilla Regis prodeunt, no pareció tampoco deste casso, porque están prohibidos los himnos en este triduo permitiéndose solamente en la Processión del Santíssimo Sacramento de mañana $[\ldots]^{55}$.

Así pues, se seleccionaron textos propios del oficio del Triduo Sacro, tomados del Libro de Isaías 53, 2-12 y de la Pasión según san Juan 19, 38-42, para Viernes Santo.

\section{Acompañamiento instrumental en el Entierro}

En el Triduo Sacro, el acompañamiento instrumental quedaba excluido por constitución, excepto el bajón y el órgano en las secciones polifónicas de las Pasiones, así como en el Miserere y el Benedictus tras los maitines ${ }^{56}$. El arpa se

\footnotetext{
${ }^{51}$ Para un análisis comparativo entre la antífona mariana Ave regina caelorum de Alonso Lobo y el motete de Guerrero Ave virgo sanctissima, véase Rory McCleery: "Duo Seraphim Clamabant: Homage, 'Parody' and Marian Symbolism in a Motet and Antiphon from Renaissance Seville", New Perspectives on Early Music in Spain, Tess Knighton, Emilio Ros-Fábregas (eds.), Kassel, Reichenberger, 2015, pp. 308-326.

52 Juan María Suárez Martos: El rito de la Salve en la catedral de Sevilla durante el siglo XVI, Sevilla, Consejería de Cultura, 2010, vol. 2 (CD), p. 18. La relación del Ms. n. ${ }^{\circ} 1$ con la Capilla de la Antigua se desarrolla en el vol. 1, pp. 64-65.

${ }^{53}$ Cummings menciona al chantre o capiscol citando a Pirotta. A. M. Cummings: "Toward an Interpretation...", p. 46. Crook menciona al rector. D. Crook: "Proper to the Day...", p. 15.

${ }^{54}$ E-VAcp, Consueta, f. 170, véase Anexo.

${ }^{55}$ Ibid.

${ }^{56}$ Constituciones..., caps. XXI-4 y XL-21.
} 
incorporó a los del Miércoles Santo ${ }^{57}$ en 1661, en 1689 también a los del Jueves y en 1690 a los delViernes Santo. En cuanto al acompañamiento de los motetes del Entierro, entre 1692 y 1698 contaron siempre con un arpista ${ }^{58}$, y con dos en 1694, 1696 y 1697. Ello significa que, junto al bajón y el órgano, en cada capilla pudo situarse un arpista, mientras que en la procesión se limitaría al bajón. En 1693 el bajonista Ignacio Muñoz recibió 3 sueldos por tocar el violón: "EnViernes Santo a Muñoz por tañer el violón enel entierro de Christo" ${ }^{59}$.

\section{De lo que se instruyó "para hazer la función del Santo entierro de Christo con cabal decencia" ${ }^{60}$ : ceremonia y espacio sonoro}

La narración del Entierro conservada en la Consueta posee un carácter similar al de las crónicas al uso en la época, consideradas por Andrea Bombi "como productos narrativos para entender mejor cómo los autores produjeron discursos con la intención de conmemorar acontecimientos con fines normativos y edificantes, y, consecuentemente, destinados a la construcción de la identidad del grupo para el que habían sido escritas [...]"61. Además de delimitar la exclusión de cantos a utilizar y textos a incorporar en la música de los motetes, ofrece un conjunto de instrucciones para su correcta preparación y celebración que nos permitirá evocar la ceremonia en su perspectiva visual y sonora. La presencia de cantores e instrumentistas colmaba el espacio de armonías que reforzarían el dramatismo de la función, haciendo suya y amplificando la carga simbólica del espacio escénico, el vestuario -"aquí en esta [Processión] del entierro de Christo cum lacrimis negrore, dolore, et aflictione est procedendum [...] hemos de usar del color morado"62-, la iluminación, las flores y la comunidad congregada allí junto a sus invitados y fieles.

${ }^{57}$ Estaba aceptado y autorizado adelantar los maitines del Triduo a la tarde del día anterior, por lo que se celebraban a las 14:30 h de miércoles, jueves y viernes.

${ }^{58}$ E-VAcp, Sacristía, Recibos, órdenes de pago, memoriales, edictos, y gasto menudo, sin catalogar. Pagos al arpista en gasto menudo de 1661 a 1706. Después de 1698 no se da indicación explícita del Entierro, pero se paga por cinco actos que lo incluían.

${ }^{59}$ Ibid. Gasto menudo, pago a Ignacio Muñoz, 20-3-1693. El Diccionario de autoridades indica de esta voz: "VIOLON. s. m. Instrumento Músico, parecido enteramente al violín, y que solo se distingue en ser mui grande, y de cuerdas gruessas, por lo que sirve de baxo en la Música, ò conciertos". "VIOLON", Diccionario de Autoridades, Tomo VI (1739) (http://web.frl.es/DA.html, consulta 21-10-2020).

${ }^{60}$ Anexo, p. XXX. Es de interés leer el documento de la Consueta completo, que se encuentra en este Anexo.

${ }_{61}$ "Chronicles are considered here as narrative products in order to gain insight into how their authors produced discourses aiming to memorialize events to normative and edificatory ends, and, consequently, directed towards the construction of the identity of the group for which they were written [...]". Andrea Bombi: "Cantaron a no más, or Musical Changes in Eighteenth-Century Spain as Constructed through Valencian relaciones de fiestas", Hearing the City in Early Modern Europe, Tess Knighton, Ascensión Mazuela-Anguita (eds.), Turnhout, Brepols, 2018, p. 182.

${ }^{62}$ E-VAcp, Consueta, f. 170r, véase Anexo. 
Pese a la austeridad del Viernes in parasceve, las gradas de la capilla donde tendría lugar el Entierro ${ }^{63}$ eran decoradas con flores artificiales e iluminadas con treinta candeleros, mientras que una cortina morada "que ay para esto solo" cubría el retablo de la Inmaculada Concepción que preside el altar. Sobre este -cubierto también por un frontal de terciopelo morado y rematado por un descendimiento de la $\mathrm{cruz}^{64}-\mathrm{y}$ entre la basa de las columnas del retablo de la Inmaculada se colocó el sepulcro ${ }^{65}$, y sobre él una imagen de medio cuerpo de la Virgen de los Dolores iluminada por seis blandoncillos. En el sepulcro, vestido con sábana colchón y almohadas, se dejaría la ya mencionada figura del Cristo obra de Gaspar Giner. Las "tres arañas, eo salomones" o candeleros, se mantuvieron encendidas tanto en la capilla como en el pórtico de acceso a la misma.

Paralelamente, el presbiterio de la capilla mayor se cubría con una alfombra negra y blanca,juntando los seis bancos de la escuela y cubriéndolos con un paño negro bordado en oro para recostar allí al Cristo yacente descubierto. El conjunto se iluminaba con seis blandones mayores, "la cabeça azia el altar maior, los pies azia la puerta dela barandilla de bronce, modo de poner a Christo sacerdote mirando al pueblo. La Santa Imagen no se cubrió ni aun con velo ${ }^{66 "}$.

La ceremonia del Entierro comenzaba al finalizar los maitines y el sermón. El asistente iniciaba la procesión, seguido por la "Santa Cruz Procesional de plata sin dorar con sus ciriales también de plata sin dorar, siguiéronla treinta Padres capuchinos con velas de tres onças [...]"'67. A los capuchinos les seguían los colegiales de beca, capellanes y sacerdotes, todos con sobrepellices y los últimos, además, estolas moradas. Finalmente salía el rector con alba y capa, junto a dos asistentes también con capa y dalmática morada: "La Capilla subió al Presbiterio, el Señor Rector y sus asistentes pusieron a la peaña del Altar maior; y estuvieron allí entre el Altar y el féretro de cara al pueblo mientras cantaron el motete a ocho Post haec autem est etc. Los seis de las estolas estuvieron junto al féretro tres a cada parte con sus manos juntas" 68 .

Para este motete a 8 voces en dos coros TiTiATe/TiATeB ${ }^{69}$, se seleccionó la Pasión según san Juan, 19, 38-39, correspondiente al día, y tema del sermón precedente, por ser "del intento para quando baxaron a Christo de la Cruz ${ }^{70 "}$

\footnotetext{
${ }^{63}$ Antiguamente había tres gradas o escalones; actualmente solo hay dos debido a una remodelación.

${ }^{64}$ No especifica si se trataba de una pintura, pero por el espacio disponible es lo más probable.

${ }^{65}$ Así queda descrito en la carta de pago de la fábrica del sepulcro.

${ }^{66}$ E-VAcp, Consueta, f. 168r, véase Anexo.

${ }^{67}$ Ibid., f. 168v, véase Anexo.

${ }^{68}$ Ibid., f. 168v-169r, véase Anexo. Los títulos están subrayados en el original.

${ }^{69}$ Las abreviaturas utilizadas de aquí en adelante corresponden a tiple (Ti), alto (A), tenor (Te) y bajo (B).

${ }^{70}$ E-VAcp, Consueta, f. 170v. El tema del sermón es mencionado en el f. 168v, véase Anexo.
} 
Texto Post haec autem. Pasión según san Juan 19, 38-3971

38 Post hæc autem rogavit Pilatum Joseph ab Arimathæa (eo quod esset discipulus Jesu, occultus autem propter metum Judæorum), ut tolleret corpus Jesu. Et permisit Pilatus. Venit ergo, et tulit corpus Jesu.

39 Venit autem et Nicodemus, qui venerat ad Jesum nocte primum, ferens mixturam myrrhæ et aloës, quasi libras centum.
38 Después de esto, José de Arimatea, que era discípulo de Jesús aunque oculto por miedo a los judíos, pidió a Pilato que le dejara llevarse el cuerpo de Jesús. Y Pilato lo autorizó. Él fue entonces y se llevó el cuerpo.

39 Llegó también Nicodemo, el que había ido a verlo de noche, y trajo unas cien libras de una mixtura de mirra y aloe.

Escrito en claves naturales, inicia los versos el primer coro en contrapunto imitativo desde su tenor hacia su tiple 1 para incorporar después al segundo coro en sentido inverso, mientras la textura contrapuntística da paso de manera paulatina a "eo quod esset discipulus Jesu" por el primer coro en textura homofónica y respondido por el segundo coro con "occultus autem" etc. Este procedimiento predomina hasta "quasi libras centum", en que finaliza el motete de nuevo con textura contrapuntística hasta llegar a la cadencia final. Obsérvense la sección "Et permisit Pilatus" y la cadencia final:

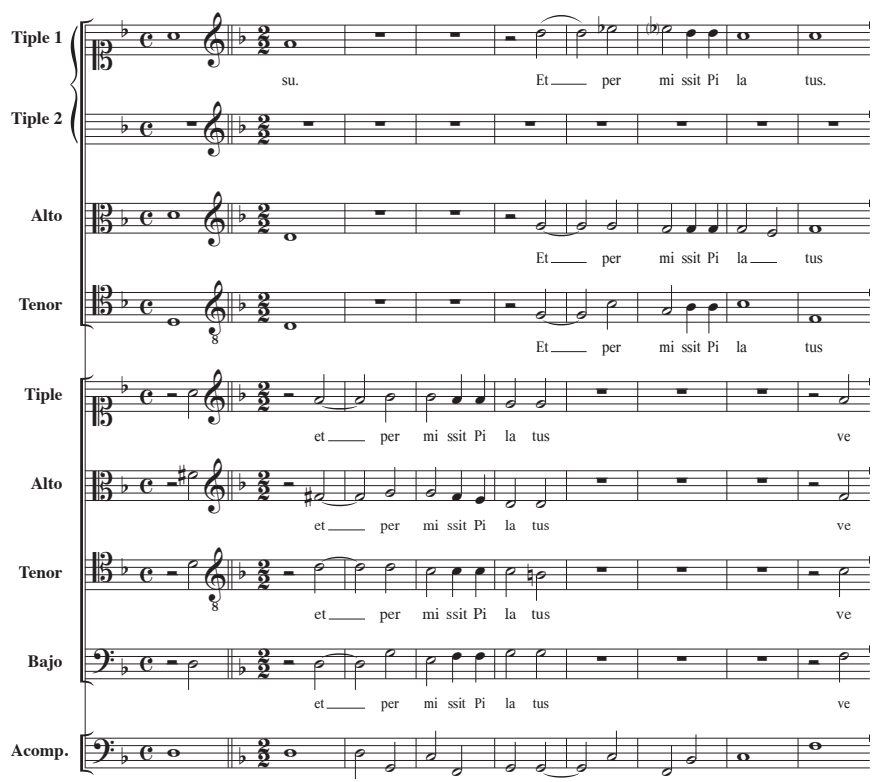

Ejemplo 1. Máximo Ríos: Post haec autem a 8, "Et permisit Pilatus", cc. 58-66

\footnotetext{
${ }^{71}$ Para las traducciones de los textos de los tres motetes se ha utilizado la Biblia de la Conferencia Episcopal (https://conferenciaepiscopal.es/biblia, consulta 25-6-2020). Los números corresponden al número de cada versículo. Los fragmentos con puntos suspensivos corresponden a versículos incompletos en los motetes.
} 


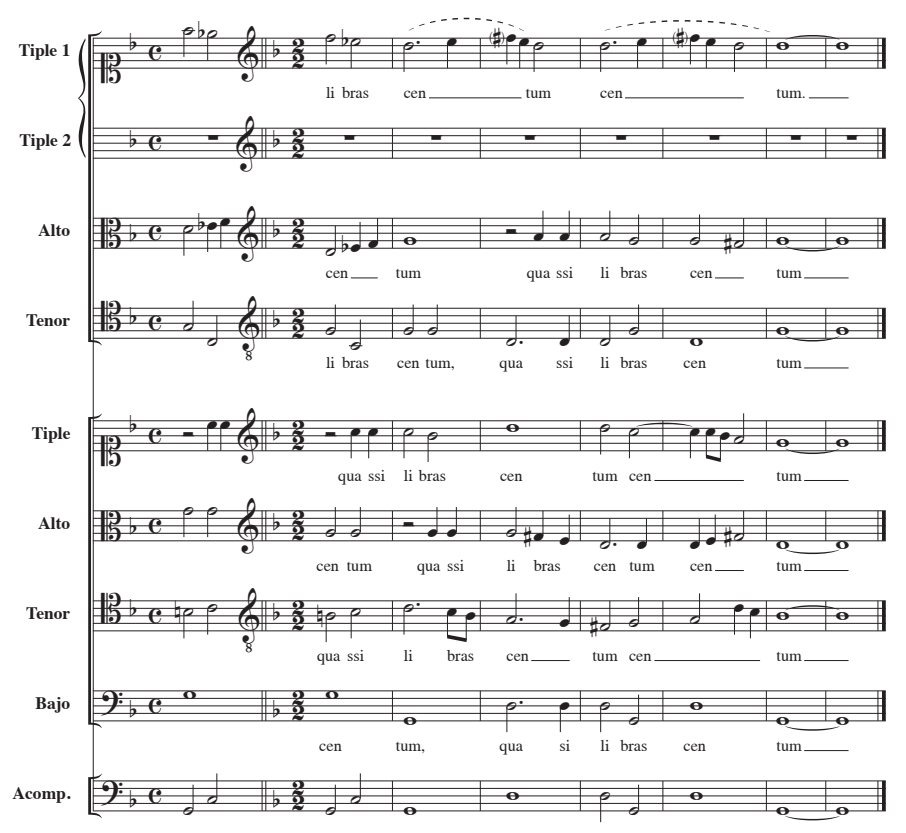

Ejemplo 2. Máximo Ríos: Post haec autem a 8, cadencia final

Al finalizar, el rector permanecía en el lado del evangelio y los sacerdotes con estola tomaban el féretro para llevarlo a la capilla del Monumento, flanqueados por dos asistentes para turnarse, "pues ay mucho concurso y pesa mucho el féretro y el trecho es largo [...]"72. Al iniciarse la procesión, los capellanes "inmediatamente empeçarán a cantar el motete a quatro: Abcissus est de terra viventium etc. y le proseguirán cantando sin cesar todo el camino hasta llegar al sepulcro [... ]"73. Este motete a 4 voces TiATeB toma fragmentos del capítulo 53 del Libro de Isaías, entre sus versículos 2 y 12, en el siguiente orden:

${ }^{72}$ E-VAcp, Consueta, f. 169r.

${ }^{73}$ Ibid. 
Texto Abscisus est, Libro de Isaías, selección de versículos cap. 53, 2-12

8. Abscisus est de terra viventium

12. et cum sceleratis reputatus est.

2. Non est species ei, neque decor,

3. Et quassi absconditus vultus eius, et despectus.

5. Ipse autem vulneratus est, propter iniquitates nostras; atritus est propter scelera nostra; disciplina pacis nostrae super eum, et livore eius sanati sumus.

4. Vere languores nostros ipse tulit, et dolores nostros ipse portavit. suum;

7. Oblatus est quia ipse voluit, et non aperuit os

6. et posuit dominus in eo iniquitatem omnium nostrum (en el manuscrito "nostrus").

11. Pro eo quod laboravit anima eius, videbit et saturabitur: in scientia sua iustificabit ipse iustus [servus meus] multos, et iniquitates eorum ipse portabit.

Domine miserere nostri.
8. Lo arrancaron de la tierra de los vivos [...]

12. y fue contado entre los pecadores [...]

2. sin figura, sin belleza [...]

3. despreciado y evitado de los hombres [...]

5. pero él fue traspasado por nuestras rebeliones, triturado por nuestros crímenes. Nuestro castigo saludable cayó en él, sus cicatrices nos curaron.

4. Él soportó nuestros sufrimientos y aguantó nuestros dolores $[\ldots]$

7. Maltratado, voluntariamente se humillaba y no abría la boca [..,]

6. y el Señor cargó sobre él todos nuestros crímenes.

11. Por los trabajos su alma verá la luz, el justo se saciará de conocimiento. [Mi siervo] justificará a muchos, porque cargó con los crímenes de ellos.

Señor, ten piedad de nosotros.

El capítulo 53 de las profecías de Isaías constituía la segunda lectura de la misa de Miércoles Santo ${ }^{74}$; sus versículos 5 y 4 (en este orden) formaban parte del responsorio de la tercera y última lectura del primer nocturno de los maitines de Jueves Santo, primera Lamentación de Jeremías. En el oficio de laudes del mismo día se citaba "et non aperuit os suum" del versículo 7 en la antífona del segundo salmo (recordemos, no obstante, que en el Colegio no se celebraba oficio de laudes), y posteriormente en el responsorio de la primera lectura del primer nocturno de los maitines de Sábado Santo, tercera Lamentación de Jeremías.

Esta selección de versículos en modo alguno debe considerarse ingenua o improvisada; los versos eran bien reconocibles por los colegiales, tanto los de la Pasión como los del Libro de Isaías, y su canto contribuiría a elevar la tensión dramática en el transcurso de la ceremonia, así como a hacer más comprensible y significativo su contenido:

El reconocimiento de otros textos en un texto litúrgico no es una experiencia desconocida para los fieles, como, por ejemplo, cuando encuentran pasajes bíblicos que han podido ser leídos en su totalidad en algún momento del ciclo de las lecciones. La reutilización podría ser una cita, alusión, paráfrasis o solo un simple detalle, y cada uno de ellos da la posibilidad al fiel de incorporar los otros textos a la interpretación del texto litúrgico que están leyendo u oyendo ${ }^{75}$.

\footnotetext{
${ }^{74}$ Actualmente Isaías 53 es la primera lectura de la celebración de la Pasión de Viernes Santo.

75 "The recognition of other texts in a liturgical text by worshippers is not an uncommon experience as, for example, when they encounter biblical passages which may have been read in full at some stage during the cycle of lections. The reuse might be a quotation, allusion, paraphrase or just the barest hint, and each of these potential-
} 
La música de este motete, escrito también en claves naturales, alterna también pasajes contrapuntísticos y homofónicos, pero su factura es más homogénea, adecuándose a la marcha procesional. Sirvan como ejemplo los primeros compases:
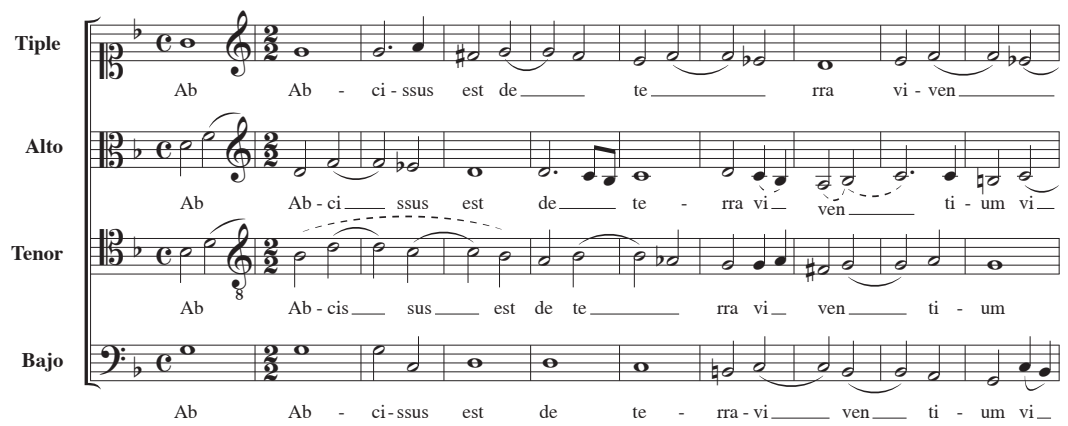

Ti.

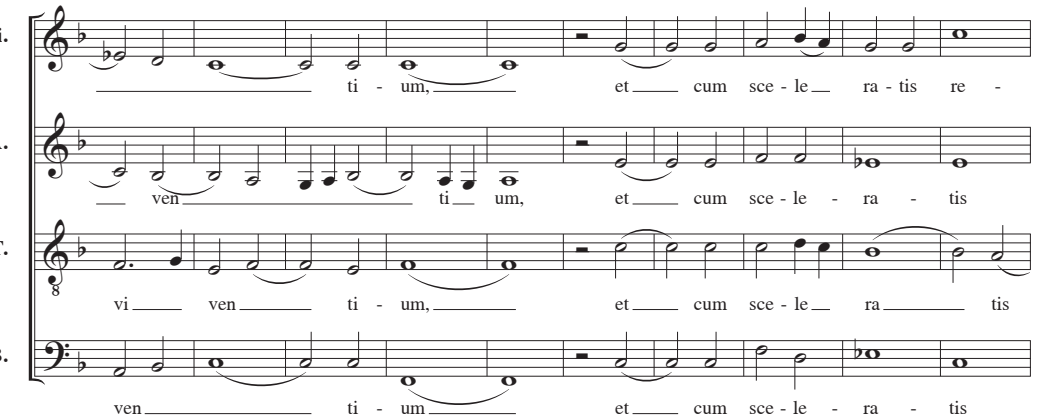

Ti.

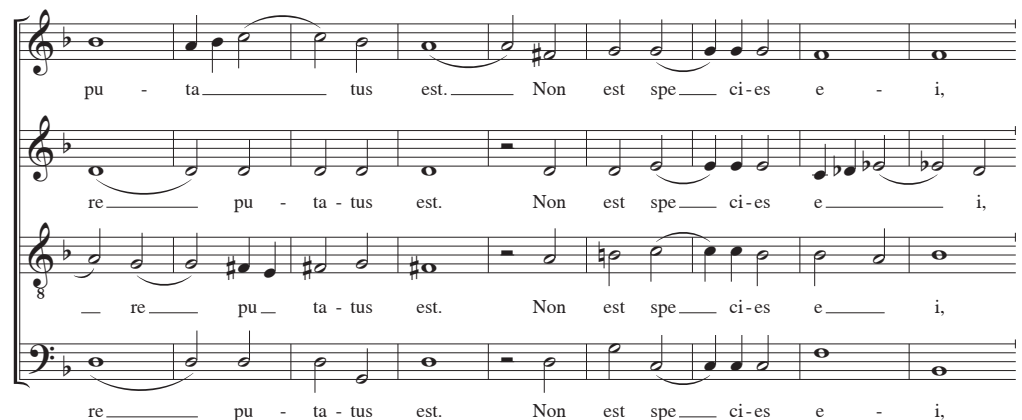

Ejemplo 3. Máximo Ríos: Abscissus est a 4,cc. 1-27

ly allow the worshipper to bring the other texts into the interpretation of the liturgical text they are reading or hearing”. Juliette J. Day: Reading the Liturgy, Bloomsbury Publishing, edición Kindle, 2014, cap. 5-Intertextualidad. 
Momentos antes de la llegada del féretro a la capilla del Monumento, el ayudante se adelantaba para sacar del sepulcro una tabla, sobre la que se colocaría el Cristo en el altar. La operación resultaba peligrosa, pues habían de subirse a dos escabeles y la figura pesaba mucho, por lo que se recomendaba "provarse tres o quatro vezes dos días antes para estar diestros, y no errarlo por que sería entonces de grande nota" "76 . A la llegada del féretro, y mientras se ponía el Cristo en el altar, la capilla comenzaba a cantar el tercer motete, Acceperunt a 8 voces en dos coros TiTiATe/TiATeB con los versículos de la Pasión de Juan evangelista correspondientes a la unción y traslado de Cristo al sepulcro: "al llegar al sepulcro y poner a Christo en él, se toma el texto de san Juan Acceperunt Corpus Iesu, que se refieren lo que hizieron, y dizen lo que hazemos" $" 77$.

Texto Acceperunt corpus Jesu, Evangelio según san Juan, 19, 40-42

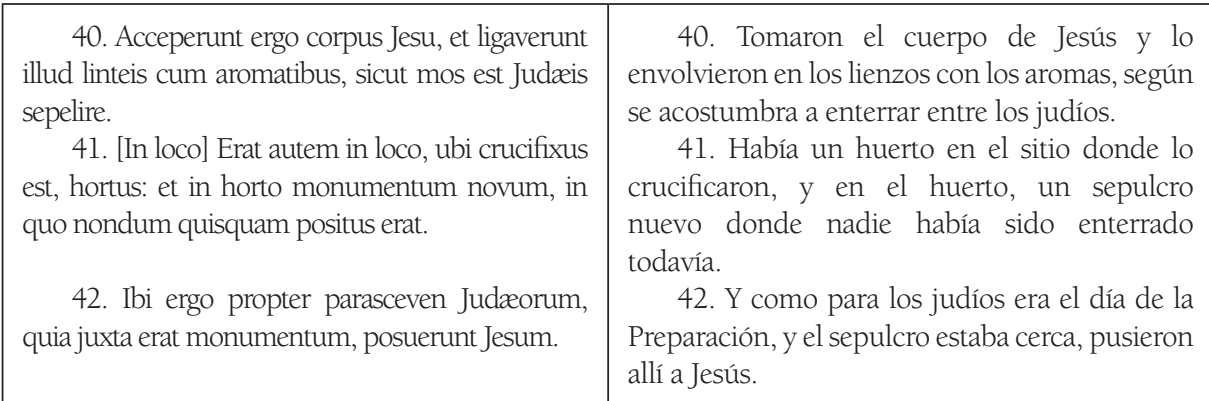

Este motete, escrito en claves altas, es de características similares a Post haec autem: presenta "Acceperunt ergo corpus Jesu, et ligaverunt illud" en contrapunto imitativo para introducir bloques homofónicos en alternancia de ambos coros hasta "posuerunt Jesum" para cuya cadencia final retorna al estilo contrapuntístico imitativo. Obsérvense los primeros compases:

${ }^{76}$ E-VAcp, Consueta, f. 169, véase Anexo.

${ }^{77}$ Ibid., f. $170 \mathrm{v}$. 


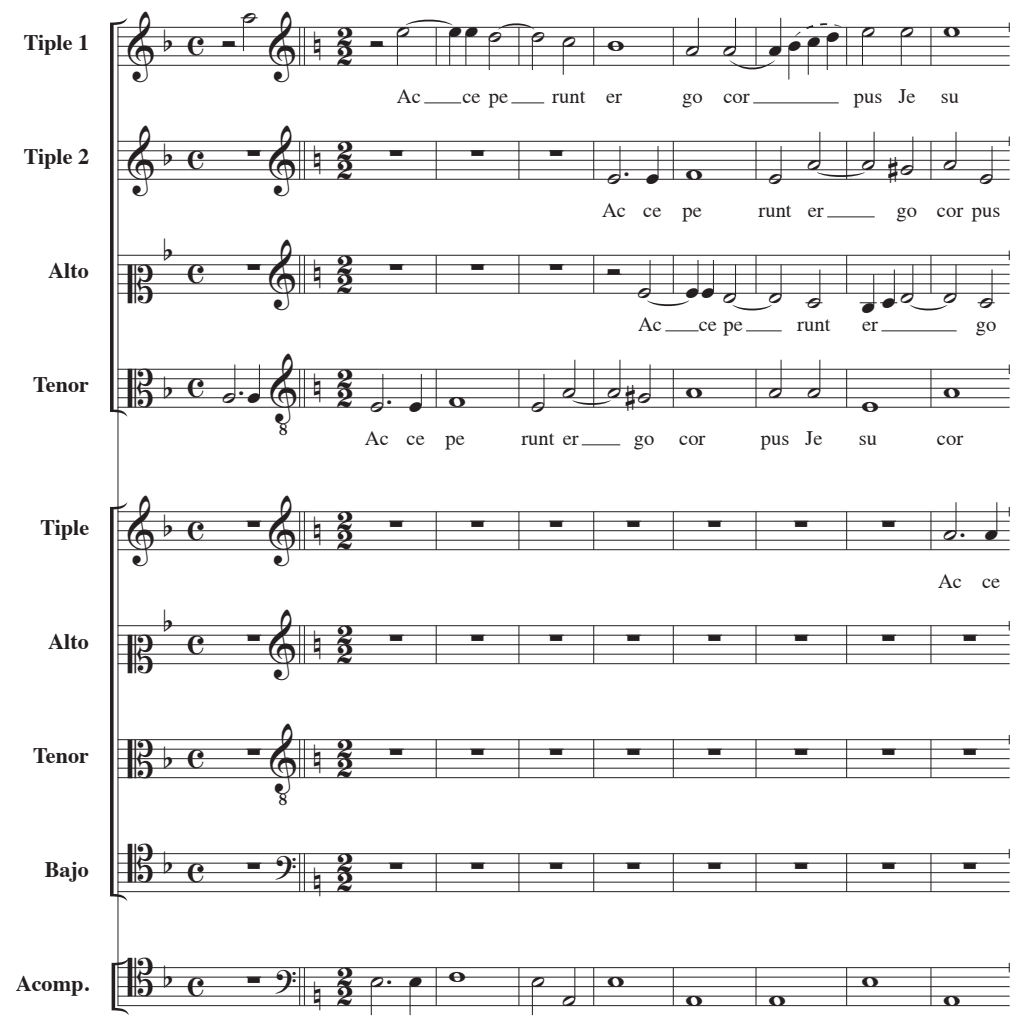

Ejemplo 4. Máximo Ríos: Acceperunt ergo corpus Jesu a 8, cc. 1-8

Una vez finalizado, el rector incensaba y tras ello y de rodillas, oraba "Respice que sumus" ${ }^{\text {"78 }}$, tras lo que se procedía a poner el Cristo en su féretro de la siguiente manera:

Dicha la oración, se levantarán el Ayudante y su compañero, y el Ayudante ará gran reverencia tomará el sudario, y con él cubrirá la cara del Santo Christo, y ambos a un tiempo con la parte de la sávana que estará doblada por atrás, cubrirán y embolverán al Santo Christo, y tirarán la tramoya, y ambos harán como como que empelen el suelo del sepulcro, y hacen entrar la Imagen en el sepulcro; y estando la Imagen dentro, tirarán dos monazillos las cortinas moradas, y el ayudante cerrará con llave las puertas del sepulcro, y después de dicha la oración, mientras

\footnotetext{
${ }^{78}$ Esta oración se solía decir tras los salmos Miserere y De profundis.
} 
se coloca la Santa Imagen, y se embuelve con la sávana y se cierra el sepulcro con llave, proseguirán cantando: Et advolvit lapidem ad ostium monumento y se volverán todos, precediendo la Cruz Procesional ala Sacristía ${ }^{79}$.

Et advolvit lapidem ad ostium monumento - "y rodó una piedra a la entrada del sepulcro", citando a Marcos 15, 46- se encuentra al final de los cuadernos del motete Acceperunt y marca el final de la representación. Su textura es totalmente homofónica con alternancia de ambos coros, resaltando el momento culminante de la ceremonia al rodar la lápida sobre el sepulcro. Obsérvese su inicio:

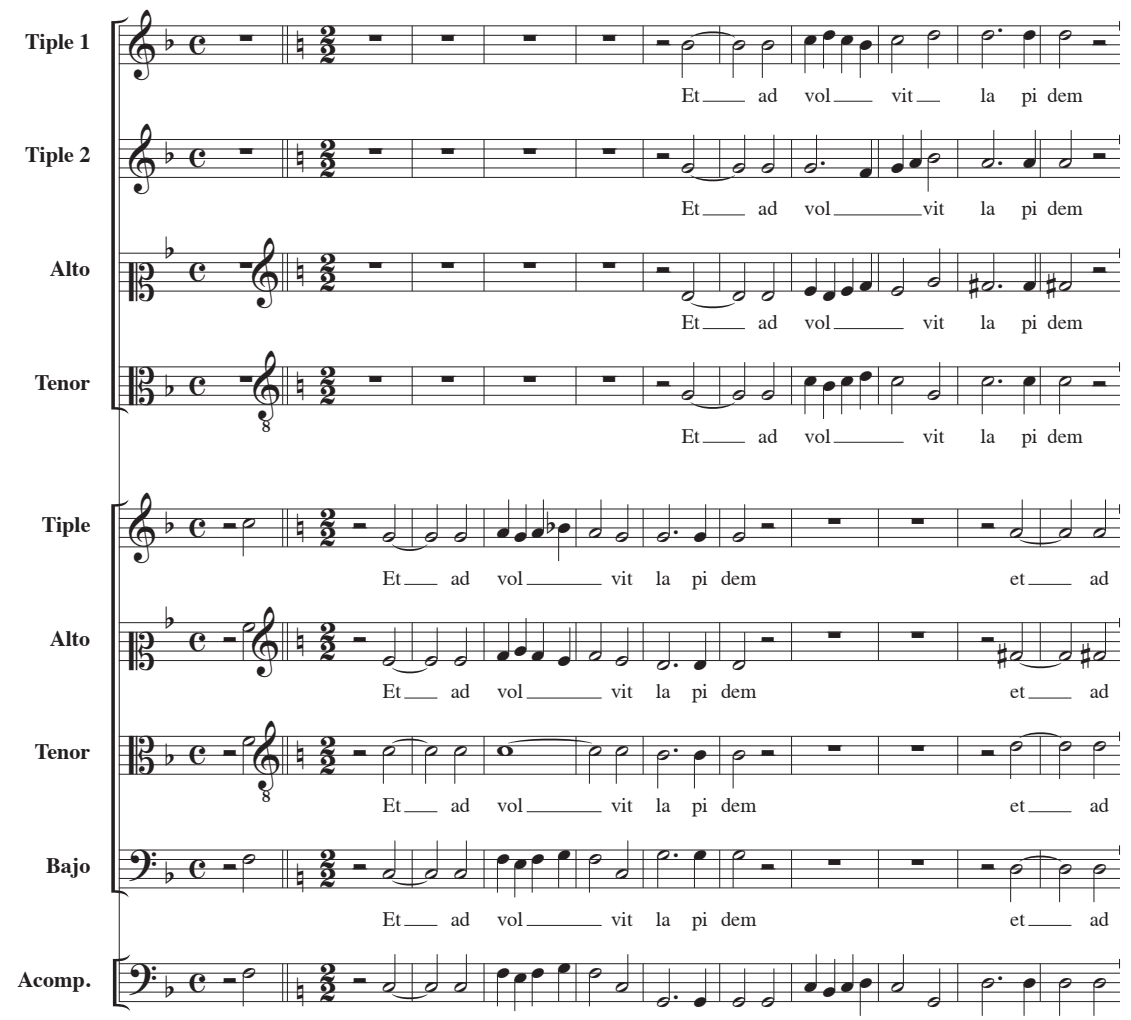

Ejemplo 5. Máximo Ríos: Et advolvit lapidem a 8, cc. 1-10

Así finalizaba la función del entierro de Cristo, un ritual que se reconocía como acto parateatral desde el principio del relato. Terminaba Isidro Planes la narración justificando el uso del color morado para esta ceremonia y aseverando que estos motetes servirían hasta indicaciones concretas de la Iglesia, pues no se podía cantar música con texto en lengua romance:"quelos que acompa-

${ }^{79}$ E-VAcp, Consueta, f. 169, véase Anexo. 
ñavan a Christo al sepulcro, o hablavan lastimados refiriendo las profecías, o interiormente lo sentirían así, y más conformándonos con los Rituales de no cantar cosas profanas [y] sí devotas [...]"80.

\section{Conclusiones}

Muchas fueron las celebraciones dramatizadas que acompañaron el cambio cultural y la reorganización de la disciplina religiosa generada por el Concilio de Trento. Si bien los debates conciliares criticaron -como se venían criticando desde épocas anteriores-celebraciones similares a la que es objeto de este artículo, la Iglesia post-tridentina reconoció la tradición en el origen de la fe cristiana, pero manteniendo una estricta supervisión de la interpretación de los textos bíblicos. La tardía celebración del Entierro de Cristo en el Colegio debe ser entendida en el contexto de una hegemonía cultural contrarreformista, con el consiguiente triunfo de prácticas paralitúrgicas que tenían en la música uno de sus más fieles aliados para reforzar el contenido didáctico.

El espacio en el que transcurre el Entierro es el adecuado a una escenificación plenamente barroca en la que no hay lugar para el vacío: reverberan voces e instrumentos dando vida a las imágenes que desde muros y bóvedas, altares y retablos, acompañan a capellanes, colegiales y fieles a lo largo del recorrido.

Los motetes atribuidos a Máximo Ríos reproducen un modelo asentado en los reinos hispánicos desde el siglo XVI para cuyo análisis disponemos de numerosos e importantes estudios, algunos de los cuales han sido presentados en este artículo. Se adaptan a una configuración tripartita de la acción -recogida del cuerpo de Cristo, traslado entre lamentos, unción y entierro-. El motete central desvela la vertiente penitencial y devocional que se corresponde con el origen del encargo, un sufragio particular, sin olvidar su vertiente teatral en el primero y el tercero.

Con este texto se ha tratado de ampliar el conocimiento de la práctica de la música litúrgica en Valencia; es necesario, no obstante, un análisis exhaustivo de esta obra y otras para la celebración del oficio de Tinieblas, prestando especial atención a los cambios producidos a lo largo del siglo XVII y XVIII, tanto en la elaboración de la polifonía como en la extensión y tipo de voces, el uso de instrumentos y de acompañamientos y la elección de los textos.

\footnotetext{
${ }^{80}$ Ibid., f. 170, véase Anexo. Las Constituciones prohibían cantar tonos profanos: "que en esta Capilla no se canten tonos profanos, ni se mezclen las canciones humanas con las divinas. Y así de ninguna manera permitimos que se digan chanzonetas [...]". Constituciones..., cap. XL-4.
} 


\section{Anexo}

[f. 167r] Narración del Entierro de Christo, que se empeçó a hazer Viernes Santo a 4 de Abril del presente año 1692 en esta Real Iglesia de Corpus Christi

Para manifestación de la grandeza desta Santa Iglesia de Corpus Christi sólo parece faltava la execución dela representación lastimosa del enternecido y lacrimable Entierro de Jesuchristo Redemptor nuestro: dichosos nos podemos llamar los que lo hemos llegado a ver, si nos valiéramos de la ocasión presente, detestando nuestros pecados, causa de la muerte de nuestro bien y Señor el Sumo Sacerdote Christo, acompañándole arrepentidos hasta su sepulcro, esperando lograr el fruto de su Passión y Resurrección por gracia perseverante, que se aprenda de la gloria que desseamos lograr de su gran misericordia amén.

Determinando que estuvo el hazerse el entierro de Christo no causó poca dificultad elegir puesto, y hazerse en él el sepulcro digno depósito de tal señor; pero quando Dios quiere todo se consigue con felicidad; tanteando se halló puesto cabal para su erección entre las dos bassis de las columnas del retablo, que sirve de Monumento, digno Mausoleo de Christo Sacramentado en el Jueves y Viernes Santo, y de los restantes del año de la Santa Imagen que le representa a Christo muerto; hízose lo que se pudo, y se logró fácilmente lo que se desseava, que era un lugar decentemente adornado para colocar la Santa Imagen que antes no le tenía. Llegósse el día tan desseado, y luego que se quitó el Santíssimo Sacramento, del Monumento se despojó de todo el adorno, y se dexó lo que pareció conducir para hazer la función del Santo entierro de Christo con cabal decencia.

Dexáronse en las dos gradas más baxas treinta candeleros delos de Almança con velas blancas de seis onzas, y las doze $i$ ? de plata [f.167v] con flores artificiales que sirven los jueves, entre puertas con las dichas velas. $\mathrm{Cu}-$ brióse el retablo con cortina morada que ay para esto solo, y sobre el sepulcro se pusso la Imagen de medio cuerpo de la Virgen delos Dolores, y ajustados los seis blandoncillos dichos delos Jueves con velas jueves. Dexáronse todas las alfombras.

Dexáronse colgadas las tres arañas, eo salomones con velas blancas las dos dentro dela capilla del Monumento, y la otra en el pórtico como se están el Jueves y Viernes Santo.

Pússose el frontal que ay rico de terciopelo morado con trepas de tela rassa, y por trofa el descendimiento de Christo Señor nuestro de la Santa Cruz, en el Altar donde está el sepulcro, y manteles limpios.

Refinóse el torno, y se acomodaron en el sepulcro la sávana para embolver la Santa Imagen a su tiempo sobre el suelo del sepulcro, y también el colchón y almohadas quedarán parejas, y se volverá a cerrar el sepulcro. 
Sobre la Messa del Altar acada ángulo se pondrá una fuente de plata y en cada una su toalla blanca de Cambray, para tomar al Santo Christo del féretro como se dirá después de el suelo del sepulcro; y en la fuente de la parte del Evangelio se pondrá el sudario de lienço para tapar la cara del Santo Christo.

Otra cosa no ha de quedar en toda la capilla del Monumento. Sí dos escabelos junto al Altar para con ellos poder colocar la Santa Imagen sobre el Altar y sin ellos no ser posible el colocarse la Santa Imagen.

En el Presbiterio de la Capilla Maior, se pusso la Alfombra negra y blanca, que ha de ser la maior, y a lo largo que toma desde la rexilla de bronce hasta la peaña del Altar, y allí se dobla por abaxo. Pussiéronse los seis banquillos a lo largo (que son los de la escuela) sobre la alfombra, y se cubrieron con el paño rico negro de trepas de oro, que era el dosel antiguo, y por venir corto, se añadió el cielo del mesmo dosel azia el Altar [f. 168r] maior, y quedó una proporcionada tarima, eo tabladito.

Colocáronse fuera del dicho paño rico los seis Blandones maiores tres a cada parte, los dos maiores junto ala peaña del Altar los dos segundos en medio, y los dos menores después azia la barandilla; a los pies del Santo Christo azia la barandilla de bronze los dos chatos triangulados; y azia la cabecera sobre la peaña del Altar los dos chatos de plata redondos. Toda la cera de los blandones y chatos era blanca.

Sobre la dicha tarima, eo tabladito cubierto con el dicho rico paño, se colocó el féretro con la Santa Imagen de Christo, la cabeça azia el altar maior, los pies azia la puerta dela barandilla de bronce, modo de poner a Christo sacerdote mirando al pueblo. La Santa Imagen no se cubrió ni aun con velo. La cera de los seis blandones dichos, y de los quatro chatos estuvo siempre encendida desde antes de ponerse la Santa Imagen en la dicha tarima, y no se mataron los cirios, ni aun quando se cantaron Maytines pues solo se matan las velas de sobre el Altar y las del triángulo según se acostumbra.

Se ha de cuidar de assear el féretro poniéndosele antes los quatro pies de tronillo, de ierro, que sobre ellos se sustenta y son necesarios. Pónesse después el colchón, átesse con las cintas porque no se desprenda, después se pone el paño rico de Espolino morado con flores de oro y plata, cúbresse con la sávana de clarín guarnecido de bonillo de Mallorca, después se componen los dos almohadas con fundas de clarín y guarnecidas de dicho bonillo, a las esquinas por adorno se ponen los lazos de oro plata y morado.

Cuydesse de prevenir el clavo con su tornillo, que passa por el colchón, paño y sávana, y se ajustará y entrará por la hembresilla que tiene clavada la Santa Imagen en sus espaldas, que con esto no puede caher la Santa Imagen del féretro y sin ello luego cahería [f. 168v] por estar el féretro más alto de la cabeça que de los pies. Cuydesse no abran las puertas de la Iglesia hasta que esté todo dispuesto como se ha dicho. 
Haviendo dado fin a los Maytines Laudes, y Misereres baxó toda la clerecía y se sentó en sus bancos, según costumbre en los demás sermones. Luego salió a predicar el Padre Mossén fray Manuel Arbustante, Mercedario calçado acompañado del Ayudante y otro capellán, precediendo quatro Acólitos y Assistentes y sin subir al Presbiterio a tomar bendición, se arrodillaron delante del Altar, y se subió al Púlpito, que estava desnudo con su tornavoz, y acabado el sermón, cuyo tema fue Post hec autem etc y vuelto el predicador a la sacristía con el mesmo acompañamiento.

Salió el Asistente de Sacristía, siguióle la Santa Cruz Procesional de plata sin dorar con sus ciriales también de plata sin dorar, siguiéronla treinta Padres capuchinos con velas de tres onças que les dieron, y se las llevaron: seguíanse los colegiales de beca y capellanes con sobrepellices y velas blancas encendidas. A los quales seguían seis sacerdotes con sobrepellices y estolas moradas de espolín de oro y plata; el Ayudante con otro capellán delante, aquienes seguían los quatro que llevaron el féretro colegiales perpetuos y capellanes, estos seis dichos no llevaban velas ${ }^{81}$, sí las manos plegadas y escondidas en las mangas de los sobrepellices. Seguíasse el Señor Rector revestido con alba y capa, y sus dos asistentes con dalmáticas, la capa y Dalmáticas dichas eran de tela morada.Todos llevaron velas encendidas excepto los seis que llevaron las estolas moradas.

La cruz Processional hizo su viaje siguiéronla los Capuchinos y se quedaron los más graves junto a las gradas de la Capilla maior sin subir nadie.

La Capilla subió al Presbiterio, el Señor Rector y sus asistentes [f. 169r] pusieron a la peaña del Altar maior; y estuvieron allí entre el Altar y el féretro de cara al pueblo mientras cantaron el motete a ocho Post haec autem est etc. Los seis de las estolas estuvieron junto al féretro tres a cada parte con sus manos juntas: dado fin al motete dicho, dexó su lugar el Señor Rector y sus dos asistentes, y se baxó y puso a los pies del Santo Christo de espaldas al pueblo, y de cara al Santo Christo se incensó estando derecho el Señor Rector tres vezes, y sin bendición more solito [simplemente la habitual]. Entre tanto que incensó fueron baxando los capellanes siguiendo la Procesión y el Señor Rector y sus dos asistentes se apartaron a la parte del evangelio, y los quatro que estavan con sus estolas tomaron el Féretro, y los otros dos Ayudantes y su compañero fueron a los lados del féretro uno a cada parte con sus manos juntas escondidas en las mangas, sin llevar velas: estos dos son necesarios si allí se escolta por si alguno se cansare tomar el féretro, o detenerse, pues ay mucho concurso y pesa mucho el féretro y el trecho es largo, porque si sucediere algo no habrá quien lo pueda remedíar.Además que son los que han de poner a Christo en el sepulcro como se dirá después.

\footnotetext{
${ }^{81}$ Margen izquierdo: "El segundo año se determinó que los dos sacerdotes que van de escolta lleven dos Sirios de los jueves para que con eso tenga la Imagen la bastante luz". Y en el margen inferior sigue: "El Señor Rector y sus dos Asistentes con cirios Jueves. assí se hizo el año 1696". El tachado está en el original.
} 
Al acabar de cantar el motete a ocho, inmedíatamente empeçarán a cantar el motete a quatro: Abissus est de terra viventium etc.Y le proseguirán cantando sin cesar todo el camino hasta llegar al sepulcro, y luego que llegarán empeçarán a cantar el motete a ocho: Acceperunt corpus Iesu etc. Antes que llegue el Santo Christo se adelantará el Ayudante en poco, y abrirá las puertas del sepulcro, y sacará la tabla que es el suelo del sepulcro, y lo tendrá ajustado, y prevenidos los dos escabelos para ponerse sobre ellos; y así como dexen el féretro con el Santo Christo sobre las alfombras, y se empeçará a cantar Acceperunt corpus Iesu [f. 169v] Le tomará el Ayudante con destreza y veneración de la cabeça teniendo la toalla en las manos, y su compañero al mismo tiempo le tomará con la toalla de los pies, y pondrán la Santa Imagen sobre la tabla dicha, que estará sobre el Altar y en su medio, y para poderlo hazer subirán de pies sobre los escabelos eo banquillos, porque si no no lo podrán colocar pues está alto y pesa muchíssimo la Imagen; y es menester provarse tres o quatro vezes dos días antes para estar diestros, y no errarlo por que sería entonces de grande nota: Puesto ya el Santo Christo sobre dicha tabla, pondrán las toallas en las fuentes, y se arrodillarán.

Acabado el motete inciensa el Señor Retor astando drecho more solito, esto es sin bendición:Y luego se arrodillan, y sin dezir versículos con media voz estando arrodillado dirá la oración Respice que sumus etc. Sin conclusión como en las oras. Dicha la oración, se levantarán el Ayudante y su compañero, y el Ayudante ará gran reverencia tomará el sudario, y con él cubrirá la cara del Santo Christo, y ambos a un tiempo con la parte de la sávana que estará doblada por atrás, cubrirán y embolverán al Santo Christo, y tirarán la tramoya, y ambos harán como como que empelen el suelo del sepulcro, y hacen entrar la Imagen en el sepulcro; y estando la Imagen dentro, tirarán dos monazillos las cortinas morada, y el ayudante cerrará con llave las puertas del sepulcro, y después de dicha la oración, mientras se coloca la Santa Imagen, y se embuelve con la sávana y se cierra el sepulcro con llave, proseguirán cantando: Et advolvit lapidem ad ostium monumento y se volverán todos, precediendo la Cruz Procesional ala Sacristía.

Nótesse, que pareció más acertado el uso de color morado que no del negro para esta función del entierro de Christo; $Y$ así el paño del féretro, almohadas, como las estolas, copa y Dalmáticas, [f. 170r] fue todo morado, siguiendo ala maior parte delas Iglesias, que para los entierros de Christo usan del color morado, y no del negro.

Y aunque no ay Rúbrica expressa que señale el color de que se ha de usar en el entierro de Christo, parece ilación de Rúbrica ser el morado el que ha de servir en el entierro de Christo, pues no es otra cossa que una Processión para representar lo que hizieron aquellos Discípulos de Jesuchristo Nuestro Redemptor colocando su humanidad separada de su Alma en un lugar sepulcral, y nosotros los católicos procesionalmente llevamos a colocar una Santa Imagen 
representativa de Christo muerto, a un lugar decente a modo de sepulcro, y esto con quebranto de nuestro coraçón aquí en esta [Processión] del entierro de Christo cum lacrimis negrore, dolore, et aflictione est procedendum... hemos de usar del color morado.

Ni obsta el que la Iglesia use del color negro para la Processión de volver al Santíssimo Sacramento Viernes Santo pues, la Rúbrica señala el uso del color morado en el oficio del tiempo a Dominica in Septuagessima usque ad Sabatum Sanctum ante Missam, exceptando la Feria Quinta ¿? A la Missa, y su annexo la Processión en que ha de servirse de color Blanco, et non amplius le señala: y en la Feria Sexta in Parasceve al oficio (que corresponde ala Missa) y su annexo la Procesión y sumpción señala el color Negro, y no se señalan los Doctores para otra función: conque como exceptio firmat regulam in contrarium, no se ha de entender a más; pues así Viernes Santo como Jueves Santo para cantar horas Diurnas, y nocturnas no ay costumbre [f. 170v] ni osamos de otro color que morado, para el entierro de morado hemos de usar, pues siendo representativas las Completas del entierro y funerales de Christo, si en las Completas usa la Iglesia enViernes Santo de estolas moradas, para el entierro no se ha de usar de otro color que morado.

Además que el color morado y el negro tienen mucha uniformidad, y es sentir de los Rubriquistas Doctos, se puede valer del morado para negro, y del color negro para funciones del morado.

Nótesse quedó assentado se cantassen por motetes en el Altar maior Post hec [haec] autem etc. Que es del intento para quando baxaron a Christo de la Cruz, síguesse el cantar por el camino Abscissus est de terra con las demás profecías de Isaías que hablan del intento, y al llegar al sepulcro y poner a Christo en él, se toma el texto de San Juan Acceperunt Corpus Iesu, que se refieren lo que hizieron, y dizen lo que hazemos. Como la Santa Madre Iglesia no tiene destinado ni señalado lo que se ha de cantar escogimos estos motetes tan del intento, y huimos de cantar el Miserere, y el In Exitu Israel de Egypto, por parecernos no convienen para esta función, pues en cantar el Miserere la Iglesia por medio de los ecclesiásticos es pedirle a Dios tenga misericordía del Alma del Difunto o difunta y la saque del Purgatorio.Y en el In Exitu sele pide lo mesmo a Dios, pues en el Egypto tierra de captividad está representado el Purgatorio, captiverio de las Almas, y por la tierra de promisión y desseada adonde desseavan llegar los Isrraelitas, está significado el cielo adonde dessean llegar las Almas, con que le piden lo mesmo a Dios que en el Miserere, impropio todo de pedirse por el Alma de Christo no bien que otros cantan Vexilla Regis prodeunt, no pareció tampoco deste casso, porque están prohibidos los himnos en este triduo permitiéndose solamente en la Processión del Santíssimo Sacramento de mañana, y como exceptio, firmat regulam etc. elegimos hasta que la Iglesia Romana señale lo que se ha de cantar, por 
parecernos más conforme, creyendo quelos que acompañavan a Christo al sepulcro, o hablavan lastimados refiriendo las profecías, o interiormente lo sentirían así, y más conformándonos con los Rituales de no cantar cosas profanas [y] sí devotas, y estas lo son tanto, como se dexan considerar, ita sentis salva Semper etc.

[Firma] Doctor Isidro Planes

Recibido: 13-2-2020

Aceptado: 15-6-2020 